\title{
Using Debate As A Pedagogical Tool In Enhancing Pre-Service Teachers' Learning And Critical Thinking.
}

Chien-Hui Yang, PhD., Nanyang Technological University, Singapore

Enniati Rusli, M.Ed., Nanyang Technological University, Singapore

\begin{abstract}
Research has shown that using debate in higher education as a pedagogical tool has effect on promoting higher order and critical thinking (Camp \& Schnader, 2010; Ng et al., 2004; Roy \& Macchiette, 2005; Ryan \& College, 2006). Debate has been implemented in various disciplines with adult learners, such as psychology (Budesheim \& Lundquist, 1999), medicine (Koklanaris, Mackenzie, Fino, Arsland, \& Seubert, 2008 ), political science (Omelicheva, 2005), marketing (Roy \& Macchiette, 2005), accounting (Camp \& Schnader, 2010), science \& technology (Scott, 2008). Based on the previous studies, students viewed the use of debate as a new and innovative way to teaching and learning, while being more informative, and eye-opening (Kennedy, 2009; Munakata, 2010). The non-traditional method of teaching also increased students' motivation and interest level (Munakata, 2010) as it gave a "real sense of drama" (Roy \& Macchiette, 2005, p. 271). However, in teacher preparation, the implementation of debate as a pedagogical tool to promote learning as well as the research on this topic is relatively limited (Erduran, Ardac, \& Yakmaci-Guzel, 2006; Ng, Lan, \& They, 2004; Munakata, 2010; Sadler, 2006).
\end{abstract}

This study aims to implement debate as pedagogical tool to enhance pres-service teachers' learning on the subject matter and investigate the effect of using debate in teacher training in Singapore context. The following research questions were posed in the study: (1) whether debate stimulated students' thinking on the subject matter more than textbook readings and lectures (traditional teacher-directed methods), (2) to which extent students' found debate helpful to their learning on the subject matter, (3) to which extent debate helped students to make connections between the subject matter and the real life, and (4) what was the qualitative feedback from students in their learning through the debate activity. Fifty-six pre-service teachers participated in a course evaluation survey to provide feedback on their learning. The results have shown that 83.9\% of teachers agree that debate stimulated their thinking more than textbook readings and lectures, while $14.3 \%$ of teachers felt neutral, and $1.8 \%$ of teachers strongly disagree. Eighty two percent of teachers found debate very helpful to their learning while $16.1 \%$ felt neutral. In addition, $80.4 \%$ of teachers agree that debate helps them to make connections between the subject matter and the real life experiences while $17.9 \%$ of teachers felt neutral. Several observations emerged from students' qualitative feedback on using debate in learning. Students expressed that the debate activity helped them to expand the understanding of the subject matter, retention of crucial concepts and knowledge, and comprehension of essential issues on the subject matter. Students felt debate helped them to understand different perspectives, and reduce bias. Some students reported change of their positions and perspectives after the debate. More importantly, many students stated that debate helped them develop critical thinking and higher order thinking skills in comparison to traditional methods.

Keywords: Debate; Teacher Preparation; Critical Thinking; Higher Order Thinking 


\section{INTRODUCTION}

\section{Significance}

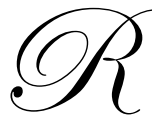

esearch has shown that using debate in higher education as a pedagogical tool has effect on promoting higher order and critical thinking (Camp \& Schnader, 2010; Ng et al., 2004; Roy \& Macchiette, 2005; Ryan \& College, 2006). Based on the literature, debate has been implemented in various disciplines with adult learners, such as psychology (Budesheim \& Lundquist, 1999), medicine (Koklanaris, Mackenzie, Fino, Arsland, \& Seubert, 2008 ), political science (Omelicheva, 2005), marketing (Roy \& Macchiette, 2005), accounting (Camp \& Schnader, 2010), science \& technology (Scott, 2008).

Budesheim and Lundquist (1999) proposed three assumptions to address the emphases and learning objectives of higher education. First, they believe that one of the outcomes of higher education is the exposure to information, ideas, and views that otherwise students would not have access to in their regular experiences. Second, students should be able consider both sides of an issue by critically analyzing their pre-existing beliefs (Budesheim \& Lundquist, 1999; Omelicheva, 2005). Third, critical and analytic skills are not naturally present in most higher education students, and thus higher order thinking activities, such as debate, are needed to instill these skills. Indeed, the success of higher education relies on the extent to which adult students are supported and guided to think critically and independently, and develop their viewpoints based on empirical evidences, theory, research, and professional values and principles. The ability to form viewpoints based on empirical evidence and professional principles, as well as the ability to understand different perspectives, are essential to adult learners' competence in working with individuals who came from different backgrounds and have different viewpoints. This paper argues that debate, when used appropriately for suitable content topics and contexts, can meet the aforementioned assumptions and learning objectives of higher education proposed by Budesheim and Lundquist.

In spite of Budesheim and Lundquist's (1999) strong points on the importance of higher order thinking in higher education, most higher education classes still tend to be lecture-based (Omelicheva, 2005; Tormey \& Henchy, 2008), even though course objectives state the development of higher-order and critical thinking skills (Omelicheva, 2005). When instructors in higher education rely mostly on lectures and teacher directed approach to deliver knowledge and skills, crucial skills such as higher order thinking and analytical skills are likely to be neglected.

Research has shown that in-class debate has been under-utilized in higher education. Omelicheva (2005) examined 130 online syllabi for undergraduate political science courses, and found that only three incorporated debate. Moreover, in teacher preparation, the implementation of debate as a pedagogical tool to promote learning as well as the research on this topic is relatively limited (Erduran, Ardac, \& Yakmaci-Guzel, 2006; Ng, Lan, \& They, 2004; Munakata, 2010; Sadler, 2006). There is a need in using debate in higher education and teacher preparation to prepare our students to face the complexity of issues surrounding the modern world and to work with individuals with different viewpoints and backgrounds. Pre-service teachers, in particular, are likely to face decisions involving parties with different options and standpoints when working with children and their families. Consequently, it is beneficial and crucial to use debate to expose them to content knowledge, help them understand different perspectives, and promote higher order thinking

\section{Debate as a pedagogical tool in higher education and teacher preparation}

The benefits of in-class debate have been well documented. Debates were used in classes where controversial issues were discussed. By being involved in debates, students were made aware of current controversial issues in their fields (Munakata, 2010). Debate requires students to be informed of the latest development in the topics of debates. In the long run, the skills inculcated could then encourage students to be active participants in their fields (Munakata, 2010), leading to teacher attribute of social responsibilities in the $21^{\text {st }}$ century (NIE, 2009).

Based on the literature, there are important benefits of using debate as a pedagogical tool in promoting learning in higher education and teacher preparation. First, the use of debate increases students' learning motivation 
and interest level on the subject matter. Research has shown that students viewed the use of debate as a new and innovative way to teaching and learning, while being more informative, and eye-opening (Kennedy, 2009; Munakata, 2010). The non-traditional method of teaching increased students' motivation and interest level (Munakata, 2010) as it gave a "real sense of drama" (Roy \& Macchiette, 2005, p. 271). A participant in Kennedy's (2009) study stated, "I think the debates will be a good change of pace and an interesting way for us to learn the information; getting involved in a lesson is a good way to help some people absorb the material" (p. 230).

Second, students found debate to be useful in reducing biases and understanding critical issues from different standpoints and perspectives. Students realized that issues were not black and white (Ng et al., 2004; Roy $\&$ Macchiette, 2005). There was "No 'universal' right way of approaching it" and the argument will likely continue in years to come" (Roy \& Macchiette, 2005, p. 13). In examining two sides of an issue, students were exposed to different perspectives, requiring them to reassess their beliefs (Budesheim \& Lundquist, 1999; Kennedy, 2009; Roy \& Macchiette, 2005). In a study with psychology students, Budesheim and Lundquist (1999) found that students who were placed in the group whose position differed from their personal beliefs, became less confident in their original beliefs or switched position. Echoing Budesheim and Lundquist's finding, Kennedy (2009) found 57.5\% of her 87 participants had switched side after debate activities. Some of these included those who defended position consistent with their original beliefs. The above research findings support that debate is a good pedagogical tool for students to view the issues from different standpoints and to reduce their biases on the issue. Debate helps students to learn about the evidences supporting both sides and reasons behind individuals' beliefs and actions. Moreover, the information learned from the debate also helps students form opinions of current controversial issues, which otherwise would have been subjected to bias due to lack of information (Kennedy, 2009). While some students repositioned their beliefs, some strengthened their convictions of original view with widened perspectives (Omelicheva, 2005).

Third, research has shown that debate is a good tool to promote higher order and critical thinking skills. Studies investigated using debates in higher education have repeatedly shown the debate to be an effective tool to bolster higher order thinking (Camp \& Schnader, 2010; Ng et al., 2004; Roy \& Macchiette, 2005; Ryan \& College, 2006;). In Scott's (2008) study with 111 college students enrolled in science, technology and society course, the participants' response to a survey question on whether the debate activity has helped them to develop critical thinking skills, yielded a mean score of 3.16 on a scale of 1 (strongly disagree) to 4 (strongly agree). Critical thinking skills are honed in all levels of the debate process (Scott, 2008). In preparing for rebuttals, the students were required to gather relevant evidence of support while thinking critically to put forth a strong argument (Munakata, 2010; Omelicheva, 2005). Students also needed to learn to use evidence and data to support their argument and viewpoints. In the performing the debate, students needed to present their argument and supporting data in well-organized and persuasive matter. Also, students were to be quick in responding to opposition (Koklanaris et al., 2008).

Fourth, the benefit of in-class debate is the expansion, retention and comprehension of content knowledge (Roy \& Macchiette, 2005). In preparation for the debate, students had to research materials from various sources, exposing them to a wider and deeper field of view regarding the topic (Kennedy, 2009; Munakata, 2010). Students in Omelicheva's study indicated understanding and making sense of complex topics as positive outcomes of the debate activity (Omelicheva, 2005). Kennedy (2009) also noted that students who participated in the debate indicated more increase in knowledge about the subject than observers (Kennedy, 2009). In a study, research results also revealed that debate assisted the retention of material (Koklanaris et al., 2008). When a group of medical residents were asked to participate in both lecture style and debate style courses, the debate group scored higher in both the tests given after the courses, as well as in the follow up quiz given 1 week later (Koklanaris et al., 2008). Consequently, debate as a teaching pedagogy demonstrated strong impact on learning outcomes.

Fifth, students in in-class debates have mentioned communication skills as a benefit of in-class debates (Munakata, 2010). Students were able to exercise and improve their public speaking skills while gaining confidence (Ryan \& College, 2006; Roy \& Macchiette, 2005). Presentation skills were utilized (hand gestures, eye contact, tone of voice; Munakata, 2010), and participants had to learn to communicate and persuade using non-verbal techniques (Roy \& Macchiette, 2005). 
Sixth, as debates are performed in groups, teamwork skills are being tested. People skills are practiced in preparation for the debate. Medical residents in Koklanaris and colleagues' (2008) study expressed a sense of "camaraderie." Other teamwork competencies that were exercised included delegation of tasks, managing different working styles, and group decision-making (Omelicheva, 2005; Roy \& Macchiette, 2005; Ryan \& College, 2006).

Moreover, in the context of teacher training, the use of in-class debate equips teachers with a teaching strategy that they are able to utilize in their own classrooms (Sadler, 2006). Erduran and colleagues (2006) found that trainee science teachers in their study did apply argumentation in their teaching (Erduran et. al., 2006). And in Kennedy's (2009) study of 87 teacher candidates, $85.7 \%$ of participants indicated in the post-survey that they would consider using debate as a classroom strategy, which was an increase from $74.7 \%$ in the pre-survey.

\section{The Singapore Context}

In Singapore, traditionally, teacher-directed approaches are utilized regularly in the education systems, from primary schools through higher education. Noticing the globalization and digital explosion of the $21^{\text {st }}$ century, the education governing body of Singapore felt the need to move forward, by preparing teachers who are equipped with $21^{\text {st }}$ century competencies, who will depart these skills to their students. The report, A Teacher Education Model for the $21^{\text {st }}$ Century (2009) published by the National Institute of Education of Singapore, delineates the changes that were made and to be made in order to produce $21^{\text {st }}$ century teachers. The report suggests the attributes of the $21^{\text {st }}$ century teaching professionals as demonstrating reflective skills and thinking dispositions, communication skills, and embracing collaborative learning and social responsibility, as well as possessing global awareness and subject content knowledge. The report mentions the shift towards a constructivist approach in teaching and learning, where student teachers are not solely dependent on the lecturers in gaining knowledge, but are instead constructors or builders of their own content knowledge (NIE, 2009). Consequently, using debate in Singapore context with pre-service teachers responds nicely to the aforementioned report. Given the lack of research findings in using debate in teacher preparation globally and in Singapore context, this current study could provide useful insights in using debate as a pedagogical tool in promoting teaching and learning.

This study aims to implement debate as pedagogical tool to deepen pre-service teachers' learning on the subject matter and investigate the effect of using debate in teacher training in Singapore. The following research questions were posed in the study: (1) whether debate activity stimulates students' thinking on the subject matter more than textbook readings and lectures, (2) to which extent students' found debate helpful to their learning in the class, (3) to which extent debate helps students to make connections between the subject matter and the real life, and (4) what was the qualitative feedback from students in their learning through the debate activity.

\section{METHODOLOGY}

\section{Participants and Settings}

Participants in this study were 56 pre-service teachers enrolled in a special education course on the topic of hearing impairment at National Institute of Education in Singapore. Before the debate, students were given readings and lectures on topics such as definition, indicators, warning signs of hearing impairments, as well as useful tips in working with students with hearing impairments. The aforementioned arrangement serves double purposes, namely to assist students obtain basic concepts on the subject matter prior to the debate, and to provide a comparison between readings/lectures (traditional teacher-directed methods) and debate (student-directed method). The debate took place in the classroom and lasted for 2 and half hours.

\section{The Controversy}

One critical issue concerning the subject of hearing impairment is the controversy between respecting deaf culture/sign language, and the use of cochlear implants (which often comes with oral training of developing speech). This controversy was highlighted through a case study on a minority family's struggle in choosing the best method for their child with hearing impairment in the United States. 


\section{The Debate Procedures}

Before the debate, students were assigned to learn about the controversy though related websites assigned by the instructor. Students were also instructed to gather information and conduct research on their own to support either side of the debate. Since students were not aware of which side they will be assigned to prior to the debate, they needed to gather information and evidence to support both sides, which was a crucial process to expand their content knowledge. On the websites provided by the instructor, students were shown graphic illustration of how cochlear implants work, the basic facts of cochlear implants, what the controversy was about, and the interviews of scholars who support either side of the debate. Students were also prompted to investigate the cost of cochlear implants in Singapore and gather local data.

At the beginning of the debate session, students were randomly assigned to either side of the debate, and a team leader for each side was elected. Students were instructed to divide their team into 3 subgroups, one for declaring position statement (rationale, overall argument), one for putting forth major argument and supportive points, and one for questioning their opponent. Students were instructed to work on conclusion statement (which comes last) together as a team. The procedures of the debate include (a) position statement from both sides, (b) questioning on the position statement of the opponent, (c) major argument from both sides, (d) questioning of the major argument of the opponent, and (e) conclusion statement from both sides. The afore-mentioned processes were adapted from Oregon-style debate procedures by the course instructor (first author of the paper). In addition, there were several grounding rules set by the course instructor, which include (a) Every member of the team needs to speak up at least once, and (b) students are expected to demonstrate professionalism and respect throughout the debate activity. The instructor would not interrupt the debate processes, unless students presented inaccurate data or made inaccurate statements on the facts on the subject matters, in which cases the instructor would stop the debate and offer brief corrections and explanations.

\section{Data Collection and Analysis}

Students were offered to answer a short survey as part of the course evaluation. Students were asked to rate on a 5 point rating scale, with 1 represents strongly disagree, 2 represents disagree, 3 represents neutral, 4 represents agree, and 5 represents strongly agree.

There were 3 statements for rating relevant to the debate: (1) the week of debate activities stimulated my thinking about the assigned material more than the assigned textbook readings and lecture format, (2) I found the debate activities very helpful to my learning, and (3) debate help me making connections between the subject (hearing impairment) and real life experiences. The data collected was then complied into SPSS software. The percentage of each rating for each question was calculated and reported.

In addition to these questions, students' qualitative feedback from the post-debate discussions and written feedback were also analyzed to reveal emerging themes. Two authors of this paper reviewed the qualitative feedback and reached consensus on the emerging themes.

\section{RESULTS AND DISCUSSION}

\section{Quantitative data} below.

In response to the research questions posted in this study, research findings were summarized and discussed

Research question 1: Whether debate activity stimulates students' thinking on the subject matter more than textbook readings and lectures.

Students experienced course readings and lectures (traditional teacher-directed methods) before debate (student-directed method). Students were asked to rate the statement "The week of debate activities stimulated my thinking about the assigned material more than the assigned textbook readings and lecture format" on a 5-point 
scale. The results have shown that $83.9 \%$ of teachers agree that debate stimulated their thinking more than textbook readings and lectures (19.6 strongly agree, 64.3 agree), while $14.3 \%$ of teachers felt neutral, and $1.8 \%$ of teachers strongly disagree.

Overall, the majority of teachers agreed that debate stimulated their thinking more than teacher directed methods such as readings and lectures. It should be noted that in Singapore context, students expressed that this was their first experience conducting debate in their education and schooling. Students got used to instructors using lectures and readings (traditional teacher-directed approaches) in teaching and learning, which may partially explain the small percentage of students $(1.8 \%)$ who didn't consider debate as more stimulating to their thinking than traditional methods. In addition, Singapore culture emphasizes heavy on harmony and respect, and discourages voicing disagreements and arguments. Hence, while the majority of the students expressed that they enjoyed the debate activity a great deal, a couple of students did express that they felt a bit uncomfortable having to disagree with their peers during the debate. For example, one student expressed that, "To me, the debate was the most daunting activity as I am not really good with 'arguing my point' and would prefer something like a discussion (exchange of views). Something that is not so confrontational... To be honest it was quite stressful for me as I am just too used to the conventional passive learning." The expression of preference on non-confrontational mode of learning is quite understandable in Singapore culture. Regardless, even the students who expressed anxiety in conducting debates, they expressed that they did learn a lot from the processes and considered it a valuable experiences in their course work, which might be the reason none of the students rated "disagree/strongly disagree" in research question 2 and 3.

Research question 2: To which extent students' found debate helpful to their learning in the class.

Students were asked to rate the statement "I found the debate activities very helpful to my learning." Eighty two percent of teachers found debate very helpful to their learning ( $8.9 \%$ strongly agree, $57.1 \%$ agree) while $16.1 \%$ felt neutral. None of the students disagree that the debate was helpful to their learning on the subject matter.

Research question 3: To which extent debate helps students to make connections between the subject matter and the real life.

Students were asked to rate the following statement "Debate help me making connections between the subject (hearing impairment) and real life experiences personally."

The results have shown that $80.4 \%$ of teachers agree that debate helps them to make connections between the subject matter and the real life experiences (25\% strongly agree, $55.4 \%$ agree) while $17.9 \%$ of teachers felt neutral. None of the students disagree on the statement.

In pre-service teacher preparation, one challenge is to help students make connection between theory and textbooks, to the real life situations. Since pre-service teachers do not have much teaching experiences to solidify their learning in the teacher preparation program, it is crucial for the instructors to make the in class learning as relevant to real life issues and dilemmas as possible. Based on the research findings in this study, the debate through a case study scenario seemed to be a good option for teacher preparation.

\section{Qualitative data}

Several observations emerged from students' qualitative feedback on what they had learned from the debate.

First, students expressed that the debate activity helped them to expand the understanding of the subject matter, retention of crucial concepts and knowledge, and comprehension of essential issues on the subject matter.

One student asserted, "I found the debate on cochlear implant to be a very effective way to learn and understand what it is all about. Unlike normal lectures, prior reading of the debate topics actually made me gain a deeper understanding of the issue." Other students also expressed that "Through the debate, I have since acquired 
in-depth understanding of what children with hearing impairment and their families face." "The debate allowed me to have a deeper understanding about the educational strategies available for students with hearing impairment." These findings were consistent with the findings in Kennedy's (2009) and Munakata's (2010) studies. In addition, a student claimed that, "I feel that with the debate organized, it helped me retained (retain) my memory on this area longer and might even be retaining (retained) forever in my memory bank." Roy and Macchiette's (2005) study reported similar findings.

Second, students felt debate helped them to understanding different perspectives, and reduced bias. These findings were consistent with previous literature (Budesheim \& Lundquist, 1999; Kennedy, 2009; Roy \& Macchiette, 2005).

In this study, students claimed "Debate helps to stimulate one's thinking, encouraging people to think out of the box. In this way, we open our door to other forms of opinions and ideas which again, encourages us to reexamine our stand for a greater insight into the topic." "The debate has allowed me to see both sides of the situation. I would try and understand the other party's perception and empathize with their situations." In addition, one student expressed, "The debate has broadened my mindset and has encouraged me to see the many perspective people have. At the end of the day though, it is not about who's right or who's wrong, but it is about learning and knowing enough to be able to make an informed decision about getting this implant."

Third, Consistent with the previous literature (Budesheim \& Lundquist, 1999; Kennedy, 2009), some students reported change of their positions and perspectives after the debate.

One student asserted, "Initially before the debate I am for cochlear implants, however, during the debate I was in the opposition side where I disagree(d) on cochlear implant. It was during the research, discussion and debate itself that I finally stood by against cochlear implantation."

The other student claimed, "Initially, I was not for cochlear implant due to the fact that there is a high risk of ear infections for children. However, through the debate discussion, I understood that the prevalence of ear infections is decreasing with proper and better immunization. Cochlear implant should not be ruled out." Hence there were a few students changed positions no matter which side they supported at the beginning.

Fourth, students felt debate helped them to develop critical thinking, which was supported by previous literature (Munakata, 2010; Omelicheva, 2005; Scott, 2008).

Students expressed that "The preparation prior to the actual debate in class compelled me to critically analyze and reflect on both sides of the situation and eventually synthese (synthesize) all the information we had as a team." "As we seek information from the internet, we are actually tapping on our critical thinking and analyzing skills. The more information I received, the more I wanted to find out more thinking critically and analyzing other aspects of information that may go against it."

Fifth, students expressed that debate helped them with higher order thinking skills, which was supported by previous literature (Camp \& Schnader, 2010; Munakata, 2010; Omelicheva, 2005; Ng et al., 2004; Roy \& Machiette, 2005; Ryan \& College, 2006; Scott, 2008).

Students asserted that "Searching for the facts or argument is one thing and having a very limited time to collate information is another. To relate the facts to the case study and deliver the information/arguments in front of the whole class takes a lot of courage. Spot on questions that needed to be answered, though there may be no wrong or right, involves higher order thinking." "The debate has definitely contributes (contributed) a higher order thinking skills for me. Normally, I would rather keep my opinion to myself and would rather not comment on topics."

Overall, the qualitative feedback in this study supported the findings from previous literature concerning the benefits of using debate in higher education. Besides, students' qualitative feedback provided first hand learner experiences in using debate as a tool in teacher preparation in Singapore context. 


\section{CONCLUSION}

This study aims to implement debate as pedagogical tool to deepen pres-service teachers' learning on the subject matter and investigate the effect of using debate in teacher training. Both quantitative and qualitative data were collected to provide insights of students' learning using debate (in comparison to traditional lectures) to develop critical thinking and higher order thinking skills in higher education and teacher preparation.

From students' point of view, the majority of students agreed that debate stimulated their thinking on the subject matter more than textbook readings and lectures, was helpful for their learning and critical thinking skills, and helped them making connections with the real life issues. When asked what they have learned from the debate activity, students' qualitative feedback also illustrated their appreciation of debate as a teaching and learning tool to help them develop critical thinking and higher order thinking skills. It should be noted that the small portion (1.8\%) of students who strongly disagreed that debate stimulated their thinking more than readings and lectures in research question 1, can be partially explained by the cultural preference of non-confrontational mode of interactions as well as the typical teacher directed instruction in education systems in Singapore.

This study aids to enrich the literature on using debate as a pedagogical tool in higher education and teacher preparation. Particularly, in Singapore context, debate offers many benefits to enhance students' communication skills, higher order thinking, and critical thinking skills that Singapore government calls for. Debate also allows the instructors an opportunity to assess students' understanding of content, and can be an indicator for changes the next lessons (Omelicheva, 2005).

The limitation of the study is the small sample size ( $=56$ ) and in one content area (hearing impairment). The future research could expand the scope of the study and investigate more in depth on the impact of debate on knowledge retention and higher order thinking skills.

\section{AUTHOR INFORMATION}

Chien-Hui Yang is an assistant professor at National Institute of Education (NIE), Nanyang Technological University, Singapore. She obtained her doctorate in Early Childhood Special Education at University of Kansas at the United States. Chien-Hui taught at the Missouri State University at the United States for 3 years before joining NIE in 2005. Her research interests include early intervention, e-learning, ICT integration in education and teacher preparation, inclusion, teacher training, evidence based practices, and early childhood education. She has several research grants focusing on ICT integration in education and teacher preparation, early childhood education, and early intervention. E-mail: chienhui.yang@nie.edu.sg. Corresponding author.

Enniati Rusli is a research assistant with the Centre for Research in Pedagogy and Practice at the National Institute of Education (NIE), Singapore. Enniati obtained her Bachelor's degree in Special Education from the University of Central Oklahoma, and her Master's in Education from the University of La Verne. Enniati taught in an early childhood special education setting for two and a half years before joining NIE. Enniati is currently involved in a research project with Chien Hui Yang (first author) investigating the use ICT in teacher training.

\section{REFERENCES}

1. Budesheim, T. L. \& Lundquist, A. R. (1999). Consider the opposite: Opening minds through in-class debates on course-related controversies. Teaching of Psychology, 26(2), 106-110.

2. Camp, J. M. \& Schnader, A. L. (2010). Using debate to enhance critical thinking in the accounting classroom: The Sarbanes-Oxley Act and U.S. tax policy. Issues in Accounting Education, 25(4), 655-675.

3. Erduran, S., Ardac, D., \& Yakmaci-Guzel, B. (2006). Learning to teach argumentation: Case studies of perservice secondary science teachers. Eurasia Journal of Mathematics, Science and Technology Education, 2(2), 1-14.

4. Kennedy, R. R. (2009). The power of in-class debates. Active Learning in Higher Education, 10(3), 225236. 
5. Koklanaris, N., Mackenzie, A. P., Fino, M. E., Arslan, A. A., \& Seubert, D. E. (2008). Debate preparation/participation: An active, effective learning tool. Teaching and Learning in Medicine, 20(3), 235-238.

6. Munakata, M. (2010). The mathematics education debates: Preparing students to become professionally active mathematics teachers. Primus, 20(8), 712-720.

7. National Institute of Education [NIE] of Singapore (2009). A teacher education model for the $21^{\text {st }}$ century. Retrieved from http://www.nie.edu.sg/files/about-nie/TE21\%20online\%20version.pdf

8. Ng, P. T., Lan, L. K. Y., \& They, J. T. E. (2004). Developing reflective teachers: The experience of two modules in the teacher training programme at the National Institute of Education, Singapore. Asia Pacific Education Review, 5(2), 2000-206.

9. Omelicheva, M. Y. (2005). There's No Debate About Using Debates! Instructional and Assessment Functions of Educational Debates in Political Science Curricula. Conference Papers -- American Political Science Association -- Teaching \& Learning, 1-40.

10. Roy, A. \& Macchiette, B. (2005). Debating the issue: A tool for augmenting critical thinking skills of marketing students. Journal of Marketing Education, 27, 264-276. doi: 10.1177/0273475305280533

11. Ryan, S. \& College, B. (2006). Arguing toward a more active citizenry: Re-envisioning the introductory civids course via debate-centered pedagogy. Journal of Public Affairs Education, 12(3), 385-395.

12. Sadler, T. D. (2006). Promoting discourse and argumentation in science teacher education. Journal of Science Teacher Education, 17, 323-346. doi: 10.1007/s10972-006-9025-4

13. Scott, S. (2008). Perceptions of students' learning critical thinking through debate in a technology classroom: A case study. The Journal of Technology Studies, 10(2), 115-119.

14. Tormey, R., \& Henchy, D. (2008). Re-imagining the traditional lecture: an action research approach to teaching student teachers to 'do' philosophy. Teaching in Higher Education, 13(3), 303-314. 
NOTES 